\title{
Critical Factors Of Success In Curriculum Enhancement In The Accounting Curriculum Using SAP R/3
}

Joseph M. Ragan, (Email: jragan@ @ju.edu), Saint Joseph’s University Patrick J. McGettigan, (Email: pjmcg25@yahoo.com), Saint Joseph's University Michael R. Storms, (Email: michael.storms@sju.edu), Saint Joseph's University Matthew G. Naccarelli, (Email: matthew.naccarelli@sju.edu), Saint Joseph's University

\begin{abstract}
Education is a well recognized aspect of an enterprise system implementation. How to educate, what to educate, when to educate, and who to educate are common questions that get raised. As an example, of particular importance in an enterprise system context is the balance between learning how to use the system itself and in understanding the integration and process concepts behind the system. As the go-live date fast approaches and budgets are running tight, firms often limit or eliminate the concepts, such as education, and focus on the keystrokes so that employees will be able to use the system.
\end{abstract}

Saint Joseph's University, a liberal arts university in the Philadelphia, Pennsylvania area, recently implemented $S A P R / 3$ within its accounting curriculum. This implementation was done in phases and at each point during the rollout, a user questionnaire was used to assess the learning skills and abilities of the students. In the early stages of this rollout, keystrokes and navigation became paramount as students learned the menu paths and reporting information available within the system. In later courses, the skills were transparent to analysis of information as students attempted to make business decisions using a case simulation. An assessment was done before and after each course, which assisted the instructors in knowing what to emphasize and when. The purpose of this paper is to outline the structure of this delivery and the lessons learned from field experience.

\section{INTRODUCTION}

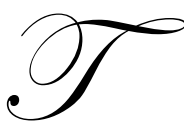

he purpose of this paper is to examine the method used to integrate the accounting curriculum with the use of SAP R/3 technology. In this paper, we will include the model of the course along with some course material.

The use of Enterprise Resource Planning systems in the business world is found in most global Fortune 500 firms which use some form of ERP with SAP and ORACLE being the leaders. Nearly 53\% of Fortune 500 companies employing ERP systems use SAP. The introduction of ERP into a company's business system greatly alters the accountant's organizational duties. Automating the Accounting Information System means the accountant no longer has to perform the time consuming functions such as recording journal entries, posting these entries to ledger accounts, and preparing trial balances. Instead, the computer is able to handle these data-processing activities on a routine basis. As a result, accountants are becoming involved in the more dynamic functions of their organizations, such as aiding in management decision making and designing more effective business information systems to enable strategic analysis.

The use of ERP systems in the accounting classroom helps to show students how a simple business transaction, such as a sales order, effects the organization as a whole. By performing transactions, the students 
become familiar with the structure of the organization, the effect the transaction has on the books (accounting), and the use of this information to solve problems.

\section{BACKGROUND AND PRIOR RESEARCH}

Albrecht and Sack (2000) paint a dismal portrait of the academic accounting profession as a discipline stuck in the past and exhibiting an unwillingness to change. They observed that technological innovation has rendered the gathering and reporting of information as an inexpensive process in today's environment. Accountants must be armed, they proposed, with new skills if they are to find a role in today's environment. They suggested that accounting educators should embrace the unfolding Internet revolution and include this experience as an integral part of the pedagogy of accounting education.

Accounting professionals also recognize this revolutionary change, and promote the implementation of higher technology for business processes. The AICPA (2000b) has made Internet usage one of its top ten technologies for the start of the new century. When professionals were asked what skill other than financial expertise was most critical for success in the accounting discipline, the overwhelming choice was Internet technology (AICPA, 2000a). Educational organizations, such as the Federation of Schools of Accountancy (1999), have offered strong recommendations for specific actions that might be taken by today's universities in an effort to improve technology education. Greater reliance on the Internet is one of the cornerstones of such proposals.

The overall conclusion to be drawn from recent literature geared toward technological integration is that the current level of exposure that accounting students have to Internet-related technologies is too limited. Tuteja (2000) notes that software applications-like enterprise resource planning (ERP) technologies - may generate great risk to educators in an environment of limited resources. Stedman (1999) determined that as colleges and universities adopted ERP applications for their own organizational management uses, they found a "secret resource" for use in the classroom. In customizing this type of system for classroom applications, some educational institutions seem to have found a unique way to attract students back to the classroom. Becerra-Fernandez, Murphy, and Simon (2000) note that demand for trained enterprise resource planning professionals has motivated a number of universities to join alliances with ERP software vendors such as SAP. The primary vehicle such vendors have to make their product work in the educational marketplace is through the Internet. Kaveney (2000) confirms that Internet capabilities enabled his own institution (Syracuse University) to substantially enrich both the curriculum and pedagogy in its business programs.

A particularly interesting point raised in literature deals with the role of accounting as a business integrator. George and Asha (2002) see ERP as the perfect vehicle to teach the supply chain and since SAP is a monolithic Accounting Information System it serves the effort well to demonstrate integration through accounting. Volkoff notes (2003) that teachers are currently developing cases to give a concrete sense of what it means to configure and develop ERP based software. The benefits derived provide even the accounting students with a unique appreciation for the challenge of information delivery in the future. Chau and Chan (2002) see ERP as the perfect vehicle to teach continuous process improvement and enhance project decision making. Their paper further calls for a systematic implementation process incorporating the tools from ERP into the classroom. Kirby (2002) notes that, ERP has essentially overcome all the implementation problems it originally experienced, and is now the vital engine by which key information is generated for the modern business. Roby, Ross, and Boudreau (2002) reports that schools are now attempting to teach integration with the use of ERP based technologies to enhance the placement of students and build stronger core skills and consulting capabilities within their students.

The issue for study, then, is how academic accountants, the educators of future professionals, should and should not use this ERP technology to educate. The first task was choosing which version of ERP to use. SAP R/3 was chosen because it has a formal University Alliance Program, of which Saint Joseph's University is a member. As a member, Saint Joseph's University receives the full ERP suite, which includes 12 major modules including forecasting, production planning, and material requirement planning areas. To date, St. Joseph's University has received over $\$ 100,000$ in grants to test the implementation of SAP in the classroom. 


\section{SAP UNIVERSITY ALLIANCE PROGRAM}

The SAP University Alliance Program for the United States, Canada, Central and South America builds upon the best components of such a program originally developed for European institutions of higher education. It has been developed by SAP America to facilitate the use of their software package (and integrated business solutions concepts) in the formal education of undergraduate and graduate students throughout the Americas. The program has grown from a charter group of five members in 1997 to over 124 member institutions as of March 2003. The Haub School of Business is proud to be among the early schools granted admission in 1998.

Upon admission to the SAP America University Alliance Program, new members receive four significant and valuable items. First, a fully functional copy of the SAP R/3 software, or the right to time-share, with a major service provider is acquired. Second, they receive copies of all professional training materials utilized by SAP. Third, one hundred days of free training for faculty members at SAP professional training classes. The amount of training is dependent upon the level of involvement that a member institution desires. Fourth, they are given access to technical support from SAP. In addition, SAP is actively working with its member institutions to ensure cooperation and sharing of course materials among member institutions.

\section{UNDERGRADUATE CURRICULUM INNOVATIONS}

Pedagogical revisions to the undergraduate curriculum in Accounting at the Haub School of Business encompass two broad categories. First, a newly created three-course sequence encompassing Intermediate and Advanced Accounting has been prepared. These courses are newly titled as FAIS I, II, and III. The three-course sequence focus is a single continuous learning experience traversing sophomore to junior year. Each course will progressively build upon and expand the knowledge base acquired in the prior course. This knowledge base will include topical content in Accounting and application ability within SAP R/3. Second, another group of courses taught in the sophomore year incorporates subject matter inherent to cost and managerial accounting. These courses are titled MAIS I an II. The SAP exposure afforded students within these course sequences will provide hands on experiences in a team-oriented format within a business case context. It is envisioned that a single business case will be used throughout these five courses.

\section{COLLABORATIVE LEARNING MODEL (STAR SCHOLARS)}

A unique feature of the course pedagogy is the utilization of STAR Scholars to assist in development and delivery of various SAP scenarios. These scholars are chosen through a highly selective process and specially trained to deal with these application scenarios. To date, there are some sixteen STAR Scholars comprised mostly of juniors and senior undergraduate majors. These students are compensated for the work done in class and are provided with enrichment activities, such as field visits and special speakers, helping them to understand the essentiality of implementation of state of the art software. They often participate in research-based projects designed and developed by faculty. In addition, STAR Scholars involve themselves in a series of special activities under the direction of a Faculty mentor. Developing scenarios of various computer applications involving Enterprise Resource Planning software and SAP are included. In addition, seminars with entrepreneurs and technology leaders to provide opportunities to interact on a personal and informal level are held with business leaders. Sponsored participation in special events with alumni working in technology and consulting fields is also a component. These students assist in classroom delivery and continue to service the course by maintaining a help desk for students.

\section{PHASES OF THE CURRICULUM ROLLOUT}

The courses are three-credit courses required for all accounting majors, typically in the sophomore and junior years. SJU requires all students to have laptops. A typical class consists of 24 students and is taught over a fourteen week semester. The university is a member of the SAP Alliance. As a member of the University Alliance, SJU is given access to SAP R/3 in real time (24/7) through the University of Wisconsin at Milwaukee. The objectives of the curriculum rollout were agreed upon by the department faculty in advance. 


\section{PHASE I - STARWALKER PHASE}

The objectives established for this phase were to better understand core business processes and their linkage to accounting. The purpose of bringing SAP into the classroom further demonstrates how the roles of accountants have changed with technology. No longer do accountants simply add and subtract, they interpret business situations and use information to make decisions. It was found that using the concept of scenarios was the most ideal way to bring business situations using SAP R/3 into the classroom and have the students enter the information, master data and transactions, then see how the system uses the information, and finally use the information to make decisions for the business.

Scenarios are written in the form of scripts and tested by the STAR Scholar Team prior to their use in class. Students just follow the script to complete the process. The typical project takes them through the following steps; master file $\rightarrow$ process $\rightarrow$ report $\rightarrow$ analyze. First they create a master file, for example, a customer or vendor master file. The students are usually asked to select a name that they will be able to identify with and remember (such as using their last name). The report would be affected by the transaction they will do in the following step. By going to the report before going through the process students see what the number was before the transaction, so when they access the report after the transaction, they can see the difference the process made. This enables the students to better analyze the effects of the process they went through. The last step is analyzing the process in terms of the effects it had on the business.

It was found that giving the students a script that has been written out and tested gives them a path to follow so they do not get lost in the vastness that SAP creates. After completing the scenario as it is written, students feel more comfortable working in the modular area in which the scenario operates. There is no such thing as an SAP expert, but there are experts in certain modules. This course was designed, not to create experts but, to make students feel comfortable when operating within the system.

A good way to create interest for the students is to use the email function within the system. This is done by emailing a question from our hypothetical employee, such as a CEO, CFO, etc., asking a question pertaining to the scenario to be performed in class. After the scenario is performed the students respond to the question which forces them to explain the task they performed and how it affected the business. Each student's response will contain an attached report, which will give the instructor enough information to give the student credit for the assignment.

It is essential for students to understand the relationship between the concept coverage within the text and the applications within SAP. A very simple overview of SAP navigation is completed in this process. The students leave with a scavenger hunt assignment using SAP navigation. Students are also introduced to the faculty website and the blackboard location for course documents and assignments. Using SAP R/3, students can now begin a walk through of the topics in the first accounting course. These topics primarily include financial statement reporting and assets. As each topic is reviewed, assignments are handed out for completion by the students, and subsequently graded. Within this first course there is an attempt to provide at least $20 \%$ of the course grade to SAP applications. It is particularly important that the students gain an appreciation of the fact that this is just the first course in which they will use SAP to enhance their study of accounting. In effect, SAP becomes the integrating factor for the entire accounting curriculum. Primary courses using SAP are financial and managerial accounting and accounting information systems. An attitude assessment conducted at this point indicates that students appreciate the more active learning approach necessitated by more hands-on computer use. In addition students realize that the computer is doing the mechanical calculations and it is their job to manage the process flow and determine where the information is going.

\section{PHASE II - STARTRACKER PHASE}

The objective of this phase is to improve information system problem solving skills using performance reports. In this phase the role of technology as a cost controller is introduced to students. The five major topics in a typical Cost Course include volume cost profit behavior analysis, standard costing, budgeting, cost center accounting (scenario demonstration provided in Appendix I), and balanced scorecard metrics. The scenarios written in these 
areas give students the opportunity to create a budget around a cost center and, as a team, measure performance and determine direction. This is done through team-based case simulations (as they now appear on the CPA exam) where students are asked to advise a client what to do regarding product cost overruns and low profitability. Student assessment surveys indicate students have a renewed appreciation on how accounting information affects management decision making and see the role non financial metrics play in shaping the performance and direction of the firm. Significant attention must be paid to the grading process in this phase. Students are not just graded in a normal test mode, but also are assessed points based on innovative and creative solutions communicated succinctly and efficiently to managers. A team presentation of project outcomes helps bring closure to the course and leads to conclusions that are often contingent and uncertain. This unstructured analysis often frustrates students.

\section{PHASE III - STARLIGHT PHASE}

The final phase for rollout of SAP is within the FAIS III course. The course has always been a series of specialty topics attempting to enhance students' appreciation of consolidated databases and the growth of international accounting standards and multinational business opportunities. Pre-surveys indicate the students have a strong inclination to use computers in every phase of their accounting homework. In addition, students have a developing, continuing interest in exploring the internet and downloading information from other data sources. Survey information still indicates a perception of accounting as mechanical and segmented. It is particularly interesting to note the strong bias toward US GAAP accounting and their proclivity to think of American accounting standards as "good" accounting.

With SAP R/3 a database called IDES is provided. This IDES group comprises four business areas. They are industry, retail, services, and banking. Each of these areas consists of sub groups which in turn consist of different companies which are broken out by country. This is ideal for teaching consolidation accounting. Each company is organized in accordance with the legal and country specific accounting requirements of the country in which it was situated. A variety of products are manufactured and sold using different distribution channels and production sites. In effect a product could be designed in one country, produced in another country, packaged in a third country, and sold in a fourth country. This integrated supply chain (typically of the manufacturing business) is ideal for teaching the importance of consolidated information and segmented information.

Students are provided a series of application problem scenarios where they have to provide information reports on the performance of the whole supply chain. They must also then be able to drill down to each component to determine contribution profit and costs. Each case is graded competitively based on project presentation correct solution and clarity of information. Post surveys indicate real satisfaction with the group work and desire to make the course even more case oriented. Given the case orientation, grades tend to be higher than a normal advanced accounting course. Topical coverage has been sacrificed in favor of a depth of knowledge of divisional information and reporting coverage.

\section{EVALUATING STUDENT PERFORMANCE}

Points are assigned to each student project for both individual assignments and the group presentation. To determine whether or not the students have completed the individual assignments, inside or outside of the classroom, the SAP R/3 system is used. There are two methods used to help keep track of what the students have completed. First, the students are given control numbers that are used throughout the semester. These numbers are used when creating their master files so that they are easier to find within the system. Second, the students have used their own names when creating master files.

The system has controls built in that enable the ability to track what user names have completed assignments. There are two ways to do this. The students can send an email using the system, and attach a transaction file number or master file number, so that it is then possible to look up those individual files in the system. Or, a list could be brought up that will show all the files created by the students. For individual projects, the latter way is found to be more efficient. For example, if the students' assignment is to create a cash account, a balance sheet account can be accessed, that has all the cash accounts listed, so it can be determined which students completed the assignment 
correctly and which did not. Because control numbers are used, and the accounts are listed in sequential order, it is easy to see which students failed to complete the assignment.

In addition to the project assignment questions, referencing and using SAP as an example to demonstrate text book material are also used on exams. Therefore, students must not only understand the textbook concepts, but also be able to identify examples using their experience with SAP to determine how this is useful or necessary for a system.

\section{CONCLUSION}

Students were generally receptive to the application scenarios in each of the phases. In surveying the students we found heightened interest due to the real world application of the material and the use of a leading ERP package. In balance, it was considered successful to implement in phases over a series of courses, as opposed to having one course exclusively dedicated to ERP and the R/3 System. The evidence from literature suggests that accounting education must change, and must change dramatically. Less time needs to be spent in comprehensive coverage and memorization of rules, and more time in dynamic exercises using technology and the internet.

\section{SUGGESTIONS FOR FUTURE RESEARCH}

What does this experience suggest regarding the future of accounting education? A more holistic approach to teaching professional accountants suggests that a framework exists over a series of courses. Topics can be divided within that framework, but must use a common theme or case. In this case, the common theme was SAP and the case was the IDES training database provided by the University Alliance. Would other topics and themes work? Active learning with technology is a major positive and has the ability to bring outside resources and alumni into the classroom to help more advanced units.

Innovation comes at a price. The need to build incentives for faculty is particularly important. The role of the STAR Scholars can not be understated. Without their assistance, hands-on activities in class and help-desk support would not be possible. The possibility of a graduate level rollout using SAP and its more advanced modules, such as Customer Relationship Management and Strategic Enterprise Management, is under consideration. It will be the used as the topic of a follow-up study.

\section{REFERENCES}

1. AICPA (2000a). "AICPA Core Competency Framework for Entry into the Accounting Profession," http://www.aicpa.org/edu/func.htm.

2. AICPA Top Ten Technologies Task Force (2000b). "The AICPA Top Ten Technologies for 2000," http://www.toptentechs.com.

3. Albrecht, W. Steve and Robert J. Stack. Accounting Education: Charting the Course Through a Perilous Future. Sarasota, FL: American Accounting Association, 2000.

4. Becerra-Fernandez, Irma, Kenneth E. Murphy, and Steven J. Simon. "Integrating ERP in the Business School Curriculum," Communications of the ACM, April 2000, pp. 39-41.

5. Chau, K Y, and S. F. Chan. "Implementing ERP through continuous improvement." International Journal of Manufactuing Technology and Management. Geneva: 2002. Vol. 4, Iss. 6; p. 465

6. Federation of Schools of Accountancy (1999). "Recommendations for the Design of Empirical Studies Examining Curricular Efforts to Develop Student Critical Thinking Skills," http://www.thefsa.org/publications/studies.htm.

7. George, Joseph and Asha George. "ERP, learning communities, and curriculum integration" Journal of Information Systems Education, 2002, Vol. 13, Iss. 1; pg. 51, 8 pgs

8. Kaveney, Michael. "Syracuse University to Have New ERP Lab," Business Journal 14 (2/18/00), p. 27.

9. Kirby, Horton. "ERP; A bearing on success." Works Management. Nov 2002. Vol. 55, Iss. 11; p. 8 
10. Robey, Daniel, Jeanna W. Ross, and Marie-Claude Boudreau. "Learning to implement enterprise systems: An exploratory study of the dialectics of change." Journal of Management Information Systems. Armonk: Summer 2002. Vol. 19, Iss. 1; p. 17

11. Stedman, Craig. "College ERP Success: May Take Custom Fit," Computerworld 33 (11/29/99), p. 12.

12. Tuteja, Akhilesh. "Enterprise Resource Planning: It Can be Risky," May 1, 2000, http://www.itaudit.org.

13. Volkoff, Olga. "Configuring an ERP system: Introducing best practices or hampering flexibility?" Journal of Information Systems Education. West Lafayette: Fall 2003. Vol. 14, Iss. 3; p. 319

\section{APPENDIX}

\section{COST CENTER ACCOUNTING}

\section{Objective 1: Create Cost Centers}

The first step in the process is to create the cost centers.

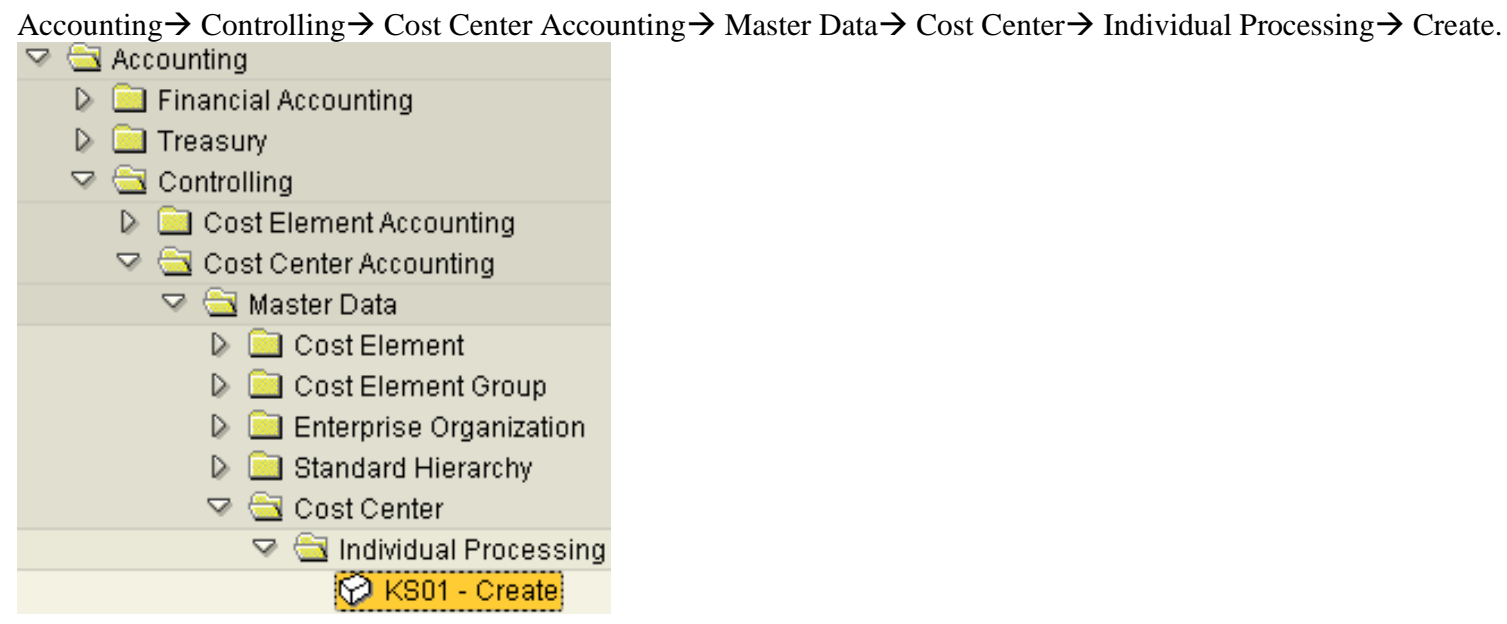

Controlling Area: 1000

a. Create Cost Center: Initial Screen

\begin{tabular}{|l|l|}
\hline Field Name & Input Data \\
\hline Cost Center & $4300-X X$ \\
\hline Valid From & $01 / 01 /$ current year \\
\hline Valid To & $12 / 31 /$ current year \\
\hline
\end{tabular}

Select Enter.

b. Create Cost Center: Basic Screen

\begin{tabular}{|l|l|}
\hline Field Name & Input Data \\
\hline Name & (Your Initials) Assembly Support \\
\hline Description & Assembly Support of Computers \\
\hline Person Responsible & (Your Name) \\
\hline Department & Assembly \\
\hline Cost Center Category & 1 (Production) \\
\hline Hierarchy Area & H1400 (Technical Area) \\
\hline Company Code & 1000 \\
\hline Business Area & 1000 \\
\hline Profit Center & 1500 (PC Products) \\
\hline
\end{tabular}




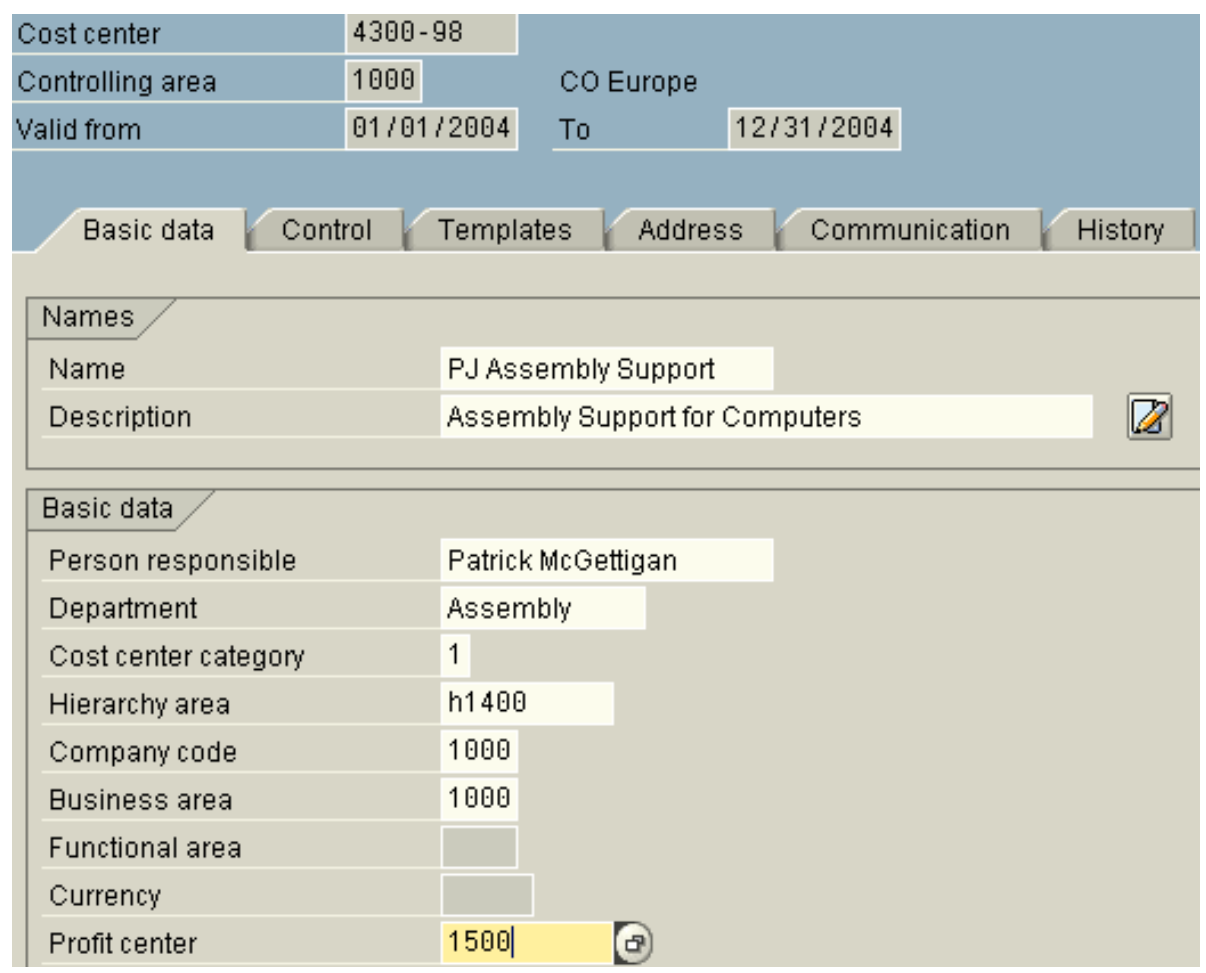

Select Save.

c. Select the yellow arrow at the top of the menu bar until you return to the SAP Easy Access Menu.

\section{Objective 2: View the Standard Cost Hierarchy} created.

The second step in the process is to view the standard cost hierarchy to see the cost center that you have

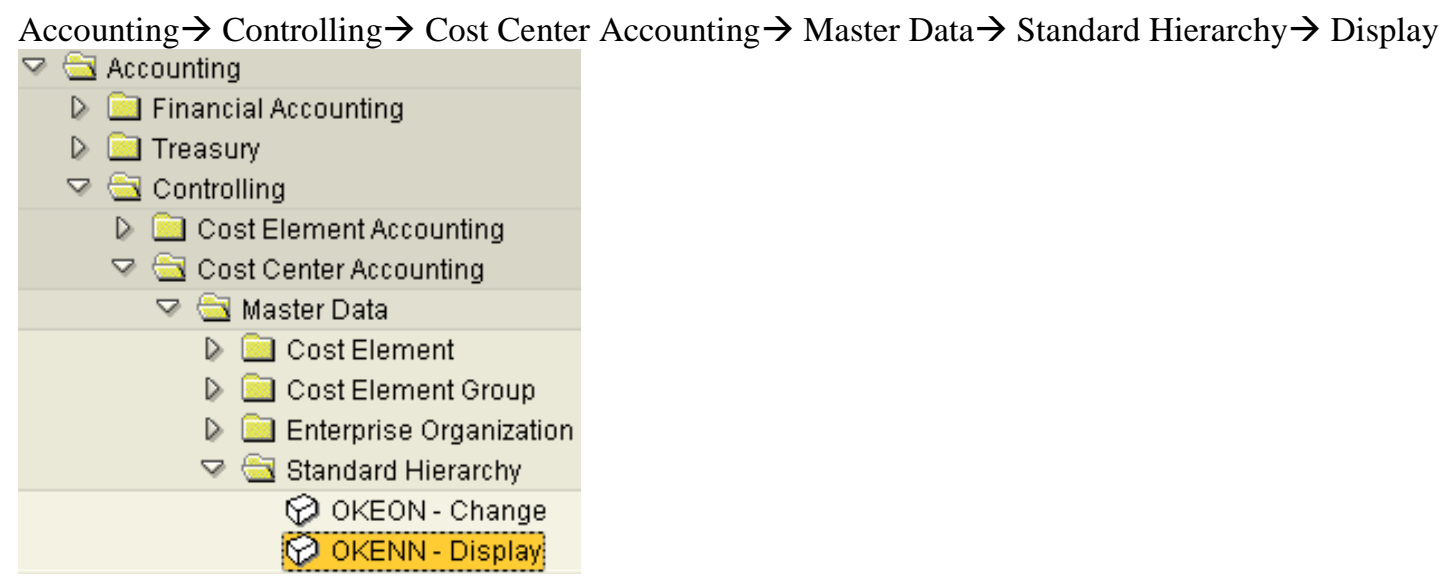

a. Under Standard Hierarchy Cost Center: H1000 Company 1000-Germany displayed. Scroll down and click on H1400 Technical Area. The cost center that you have created is located here.

b. Select the yellow arrow at the top of the menu bar until you return to the SAP Easy Access Menu. 


\section{Objective 3: Create Planned Costs}

The third step in the process is to set up planned costs in your cost centers for several general ledger accounts.

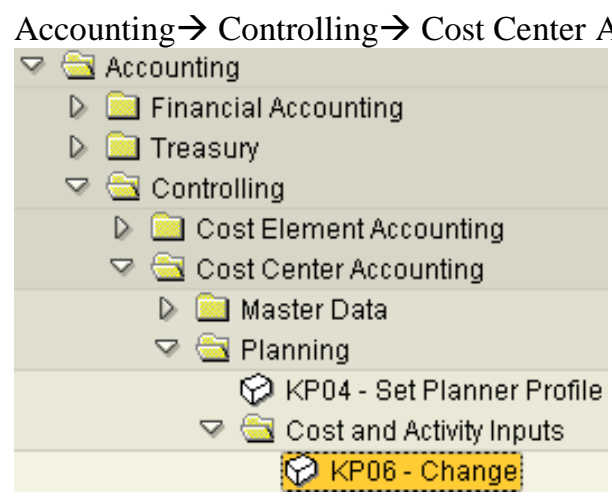

a. Change Activity Type/Price Planning: Initial Screen

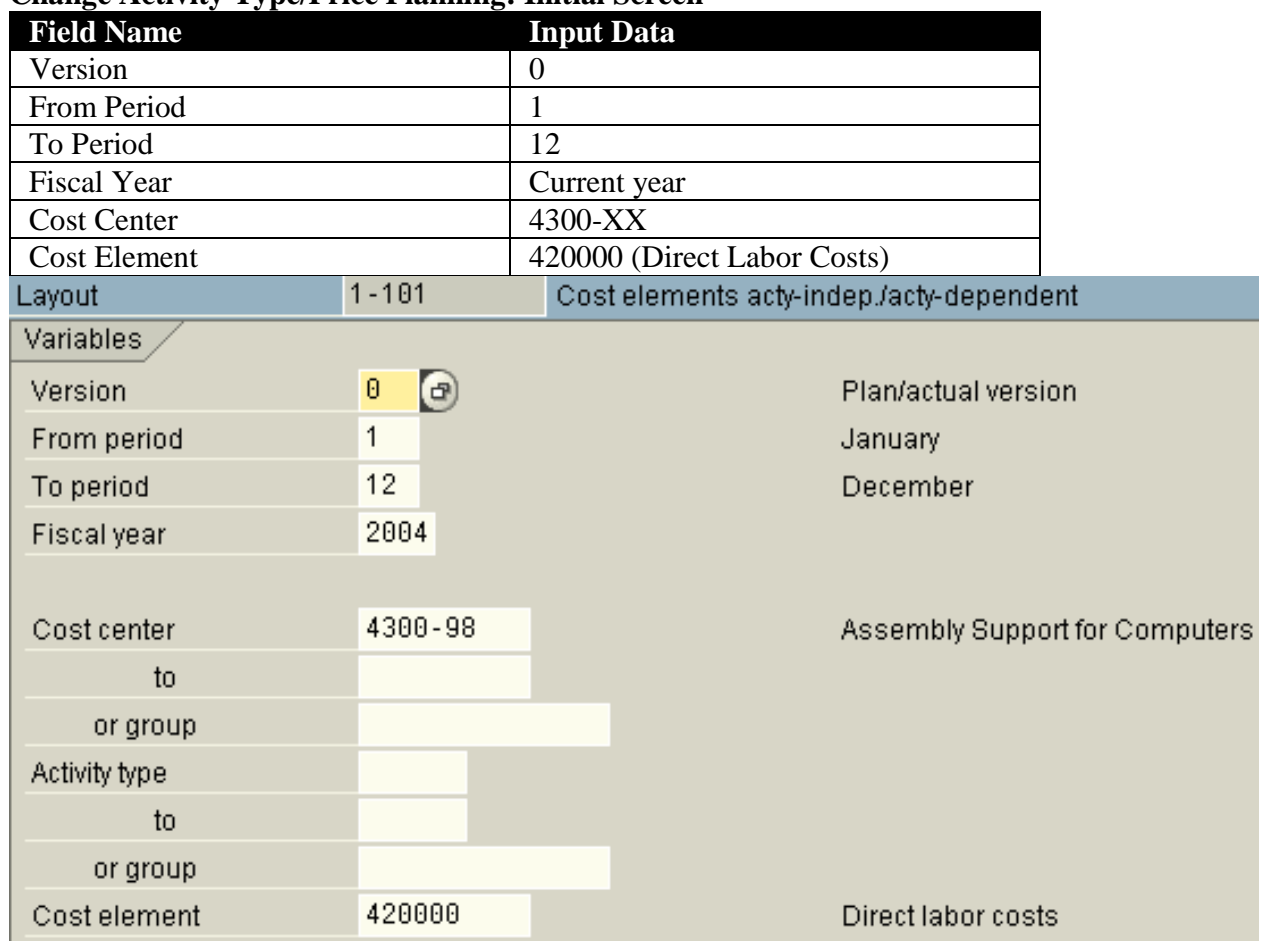

Select the Overview Screen $\triangleq$ (sun and mountain icon). 
b. Change Cost Element/Activity Input Planning: Overview Screen

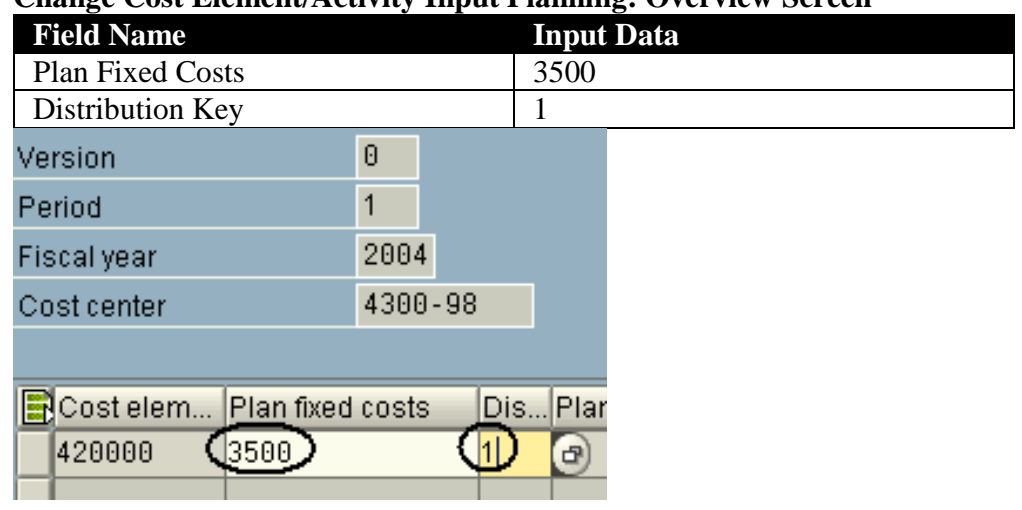

Select Save.

Repeat this step twice more using the following cost element and relative plan fixed costs

\begin{tabular}{|c|l|l|l|}
\hline Field Name & Cost Center & Cost Element & Plan Fixed Costs \\
\cline { 2 - 4 } Input Data & $4300-\mathrm{XX}$ & 430000 (Salaries) & 4500 \\
\cline { 2 - 4 } & $4300-\mathrm{XX}$ & 473120 (Telephone Usage) & 2000 \\
\hline
\end{tabular}

c. Select the yellow arrow at the top of the menu bar until you return to the SAP Easy Access Menu

\section{Objective 4: Record Transaction} created.

The fourth step in the process is to record a transaction that will affect the two cost centers that you have just

Accounting $\rightarrow$ Financial Accounting $\rightarrow$ General Ledger $\rightarrow$ Document Entry $\rightarrow$ Enter G/L Account Document

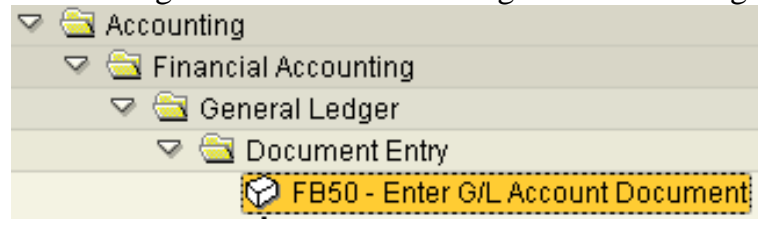

a. $\quad$ Enter G/L Account Document: Company Code 1000

Click on the Basic Data tab and enter the following information:

\begin{tabular}{|l|l|}
\hline Field Name & Input Data \\
\hline Document Date & (Today's Date) \\
\hline Currency/Rate & EUR \\
\hline Company Code & 1000 (Should Default) \\
\hline
\end{tabular}

If it doesn't default go to Edit $\rightarrow$ Change Company Code $\rightarrow$ change to 1000

Actual Costs

In the Items section, enter the following information:

\begin{tabular}{|l|l|l|l|l|l|}
\hline Field Name & G/L Acct & D/C & Amount in Docc. Curr. & Tax Code & Cost Center \\
\hline \multirow{3}{*}{ Input Data } & 420000 & $\mathrm{D}$ & 3200 & & $4300-\mathrm{XX}$ \\
\cline { 2 - 7 } & 430000 & $\mathrm{D}$ & 4400 & & $4300-\mathrm{XX}$ \\
\cline { 2 - 7 } & 473120 & $\mathrm{D}$ & 2100 & $\mathrm{~V} 0$ & $4300-\mathrm{XX}$ \\
\hline \multirow{2}{*}{} & 110000 & $\mathrm{C}$ & 9700 & & \\
\hline
\end{tabular}




\begin{tabular}{|c|c|c|c|c|c|c|c|c|}
\hline Basic data & Details & & & & & \multirow{2}{*}{\multicolumn{3}{|c|}{ Total deb. }} \\
\hline & & & & & & & & \\
\hline Doc. date & $04 / 27 / 2004$ & \multicolumn{2}{|c|}{ Currncy } & \multicolumn{2}{|l|}{ EUR } & & $9,700.00$ & \multirow[t]{2}{*}{ EUR } \\
\hline Posting date & $04 / 27 / 2004$ & & & & & & & \\
\hline Reference & & & & & & \multicolumn{2}{|c|}{ Total cred. } & \\
\hline Shrt tat & & & & & & \multicolumn{2}{|r|}{$9,700.00$} & EUR \\
\hline Cross-comp.no. & & & & & & & & \\
\hline Company code & \multicolumn{4}{|c|}{1000 IDES AG Frankfurt } & & \multicolumn{2}{|l|}{$\infty 00$} & \\
\hline \multicolumn{9}{|c|}{ Items (Standard 1) } \\
\hline ESt... GiL acct & Short text & Dic & Amol & unt in doc.curr. & T.. & Tax jurisdictn code & W Text & Cost center \\
\hline d 420000 & Direct labor.. & Debit $\underline{\underline{t}}$ & & $3,200.00$ & & & & $4300-98$ \\
\hline 2 430000 & Salaries & Debit $\underline{ \pm}$ & & $4,400.00$ & & & & $4300-98$ \\
\hline 473120 & Telephone ... & Debit $\underline{\underline{t}}$ & & $2,100.00$ & Vo & & & $4300-98$ \\
\hline d 110000 & Checking a... & Cred..t & & $9,700.00$ & & & 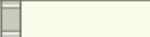 & \\
\hline
\end{tabular}

You might have to scroll over to enter the cost center info Select Save.

Record the Document Number:

b. Select the yellow arrow at the top of the menu bar until you return to the SAP Easy Access Menu. "Do you want to exit?" $\rightarrow$ Yes

\section{Objective 5: Display Transaction Document}

The fifth step in the process is to display the transaction document that you have just created.

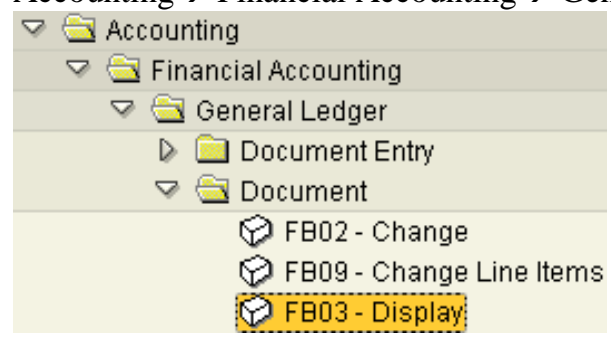

a. Display Document Initial Screen

Field Name $\quad$ Input Data

\begin{tabular}{l|l} 
Document Number & (Should Default) \\
\hline
\end{tabular}

Select Enter.

b. Select the yellow arrow at the top of the menu bar until you return to the SAP Easy Access Menu.

\section{Objective 6: Review Cost Center Report}

The sixth step in the process is to examine the actual costs that are contained within your two cost centers.

Accounting $\rightarrow$ Controlling $\rightarrow$ Cost Center Accounting $\rightarrow$ Information System $\rightarrow$ Reports for Cost Center Accounting $\rightarrow$ Plan/Actual Comparisons $\rightarrow$ Cost Centers: Actual/Plan/Variance. 
a.

Cost Centers: Actual/Plan/Variance: Selection

\begin{tabular}{|l|l|}
\hline Field Name & Input Data \\
\hline Controlling Area & 1000 \\
\hline Fiscal Year & 2004 \\
\hline From Period & 1 \\
\hline To Period & 12 \\
\hline Plan Version & 0 (Plan/Actual Version) \\
\hline Cost Center Value & $4300-\mathrm{XX}$ \\
\hline
\end{tabular}

Select Execute.

b. Select the yellow arrow at the top of the menu bar until you return to the SAP Easy Access Menu. "Do you want to exit?" $\rightarrow$ Yes

\section{REQUIREMENT}

Send Art Vandelay your cost center report and in the memo identify key output elements for Art and how this variance report should be used as a management tool. 